\title{
Study on Channel Selection Evaluation Model of Painting Material Industry Based on Brand Building
}

\author{
Wen Li, Wenbo Wang \\ School of Business Administration, South China University of Technology, Guangzhou, China \\ Email: 18814110204@163.com
}

Received 27 September 2015; accepted 17 October 2015; published 20 October 2015

Copyright (C) 2015 by authors and Scientific Research Publishing Inc.

This work is licensed under the Creative Commons Attribution International License (CC BY). http://creativecommons.org/licenses/by/4.0/

\section{(c) (i) Open Access}

\begin{abstract}
By briefly reviewing relevant theories and studies about marketing channel evaluation and directing at the channel characteristics of painting material industry, this paper discusses how enterprises choose competitive marketing channels from the angle of brand building. Studies are carried out from three aspects which are economic efficiency, stability and expansibility of channels, and an evaluation index system of selecting channel members in painting material industry is established. Besides, comprehensive evaluation is conducted for distribution efficiency, transaction cost, cooperative intention, operation capacity, competitive capacity and sustainable development capacity of channels through 18 indexes. Moreover, evaluation model of channel selection in painting material industry is constructed via analytic hierarchy process.
\end{abstract}

\section{Keywords}

Painting Material Industry, Channel Selection, Brand Building, Evaluation Index System

\section{Introduction}

The rapid growth of stationery market demand in China has promoted expansion of painting material industry scale, and its growth potential is huge. At present, China has about 186 million primary and secondary school students, 23.86 million undergraduate and graduate students, and about 34 million people in 8 million enterprises and public institutions. Thus, a large-scale office stationery consumer market is formed owing to the huge education and office class. Meanwhile, with further development of cultural education and commercial activities in the future, China's painting material industry is bound to present a stable and fast development trend.

However, due to the low entry threshold of painting material industry, numerous capitals swarm into China, 
and the industry channel becomes crowded and disordered. Besides, with the differentiation of enterprise competition mode, channel competition becomes more intense. Competition for dealer resources and terminal resources has seriously restricted the survival and development of painting material enterprises. When multiple products with the same quality squeeze each other in the dealers' channel network, channel partners often select salable famous brands with huge profit margin as leading product. Some local brands or minority brands with small profit margin become victims in channel competition, and they are treated as image or sales promotion means by channel partners to attract customers.

For painting material industry with extremely severe product homogeneity, only channel and brand can bring about differentiated competitive advantages. Channel selection should cooperate with and support brand promotion. An effective channel cannot only realize terminal marketing of products and services, but also provide a basic platform for brand communication and building. Brand promotion will further accelerate the virtuous cycle of channels and make channels realize rapid and effective expansion and perfection [1]. Therefore, by directing at channel characteristics of painting material enterprises and combining with the existing theoretical researches, this paper analyzes the channel selection behavior of painting material enterprises and establishes a marketing channel selection evaluation model of painting material industry by considering the relation among factors like marketing channel and brand building. It cannot only improve the disordered channel situation of painting material industry, but also can help enterprises select competitive marketing channels. Besides, it has important theoretical guidance significance for improving brand awareness of domestic painting material enterprises and promoting industry development.

\section{Literature Review}

The American marketing scholar Louis W., Stern Adel, et al. (2001) investigated the performance of marketing channel from three aspects which were benefit, efficiency and fairness via financial analysis method [2]. Li, J.J. (2010) considered that a good channel should be able to help enterprises realize product and service transfer and maximize the customer value at the lowest cost and highest efficiency, so channel revenue maximization was the ultimate goal pursued by enterprises during channel selection. She evaluated channel performance from the aspects of financial conditions, channel state, customer value and channel value [3]. Han, L.J. and Fan, G.Y. (2006) studied marketing channel evaluation from the angle of strategic development, and considered that competition and development ability of the channel should be considered during channel evaluation [4]. Wang, Y.J. (2007) added learning ability and innovation ability of the channel into the existing channel selection evaluation indexes and treated channel as a system in dynamic development, which had strategic development significance for evaluation researches of channel selection [5]. Ye, N. (2013) thought that enterprises should determine the selection standards during channel selection, and pay special attention to marketing ability, operation ability and general environment of the channel. He established a channel selection evaluation model by adopting grey connection decision-making method, and conducted empirical researches. Besides, he sorted different alternative channels according to the value of grey correlation degree gained by calculation, so as to make the best channel decision for enterprises [6].

Generally speaking, domestic and overseas studies about channel evaluation have experienced evaluation for middleman performance with quantified financial indexes at the beginning, evaluation for overall efficiency of channels by combining quantitative and qualitative indexes, and strategic evaluation that emphasizes channel development and innovation. Scholars' studies on channel evaluation are perfected gradually with the changes of environment and development of marketing. However, most previous academic researches on marketing channels often focus on performance evaluation for the existing channels of enterprises. The established index system evaluates whether the enterprise channel is reasonable and effective from the angle of history, and it does not directly guide channel selection of enterprises. Few scholars study how enterprises judge whether the channel can be entered when selecting new channels, and in the few academic researches on channel selection, the influence on brand building of the enterprise is ignored during channel member selection.

\section{Channel Selection Evaluation Index Construction of Painting Material Industry}

\subsection{Channel Characteristics of Painting Material Industry}

Painting material industry often adopts direct marketing channels, including marketing channels directly facing 
retailers such as large supermarkets, shopping places, discount stores, gift stores and bookstores. Generally speaking, the most important marketing channels of painting material industry are chain supermarkets and (small) stationery exclusive shops near schools and residential quarters, which occupy more than $50 \%$ shares. The channel characteristics are mainly reflected in the following three points.

Firstly, the channels tend to be flat and market competition gradually turns into the pattern of "retail as the king”. The purpose for channels of painting material industry to become flat is to reduce the number of dealers, to avoid unnecessary cost caused by intermediate links, to enhance channel efficiency, and to increase the industry profitability. The retail threshold is low. With the increase of market purchasing power, the retail industry of painting materials will gain further development. Strengthening of the existing retail store integration makes customer demand orientation of the industry more obvious. Painting material manufacturers like True Color, M\&G and Pilot directly provide purchase and distribution businesses for retail stores like stationery boutiques/ office stationery stores. These well-known product manufacturers have strengthened control for wholesale and retail links, and cut down the profit margin of wholesale market. In the long run, the wholesale market will die out and market competition will gradually turn into the pattern of "retail as the king".

Secondly, the overlapping phenomenon of dealer brands is serious and homogeneous products just squeeze each other in the channel network. According to the current competition pattern of painting material industry market, most channel resources focus on painting material products of international brands with high popularity, but brand overlapping phenomenon is quite severe in the product structure of most dealers. When dealers operate high-end international brands like Crayola and Faber-Castell, they will also involve some domestic famous brands like M\&G, True Color and Comix as well as other domestic brands at a low price. Besides, with the increase of consumer purchasing power, enhancement of brand awareness and rationalization of consumption idea, channel extrusion phenomenon will ultimately eliminate some brands.

Thirdly, e-commerce becomes the general trend of channel development in painting material industry. The rise of network consumption has created new development opportunities for e-commerce of painting material industry. Faced with the drastic market competition, painting material enterprises need to deal with the challenges through transformation and upgrading. Developing a new marketing channel is the key to winning in the fierce competition, and e-commerce is undoubtedly the first choice of new channels. At present, most painting material enterprises have carried out online businesses, and joined large-scale B2C online retailers like Amazon, dangdang.com, JD.COM and tmall.com. Now e-commerce channel still occupies a low share among marketing channels of the industry, but its future development potential is huge.

\subsection{Construction of Channel Selection Evaluation Index System of Painting Material Industry}

By directing at the above analysis on channel characteristics of painting material industry and combining with the existing theories and channel selection evaluation indexes in academic circles of marketing, this paper constructs a channel selection evaluation index system of painting material industry from three aspects which are economic efficiency, stability and expansibility of channels. Besides, comprehensive evaluation is conducted for distribution efficiency, transaction cost, cooperative intention, operation capacity, competitive capacity and sustainable development capacity of channels through 18 indexes, as shown in Table 1.

1) Evaluation on economic efficiency of channel. Economic efficiency means to gain the maximum benefit with the lowest cost in daily operation. The average profit rate of painting material industry is low, and fierce competition among dealers makes enterprises greatly increase the input in channel cost. An effective channel should be able to optimize the channel cost and realize a win-win result between manufacturers and dealers. Therefore, evaluation on economic efficiency of channel is very important for painting material enterprises. Economic efficiency of channel is mainly reflected in sales volume that can be realized by the channel and cost required to generate profit. This paper investigates the economic efficiency of channel from two aspects which are distribution efficiency and transaction cost of channel. The distribution efficiency index covers marketing capacity, terminal coverage rate and marketing service level; transaction cost includes search cost, negotiation cost and implementation cost.

2) Evaluation on stability of channel. Stability of channel means the ability of the channel to normally exercise transition and circulation functions, and channel crisis will not happen under the influence of various uncertain factors [7]. Generally speaking, painting material enterprises repeat distribution network construction of 
Table 1. Marketing channel evaluation indexes of painting material enterprises.

\begin{tabular}{|c|c|c|c|}
\hline Goal Layer & Sub-goal Layer & Criterion Layer & Index layer \\
\hline \multirow{18}{*}{$\begin{array}{l}\text { Effectiveness of } \\
\text { channel selection }\end{array}$} & \multirow{6}{*}{$\begin{array}{l}\text { Economic efficiency } \\
\text { of channel }\end{array}$} & \multirow{4}{*}{ Distribution efficiency } & Marketing capacity \\
\hline & & & Terminal coverage rate \\
\hline & & & Marketing service level \\
\hline & & & Search cost \\
\hline & & \multirow[t]{3}{*}{ Transaction cost } & Negotiation cost \\
\hline & & & Implementation cost \\
\hline & \multirow{6}{*}{ Stability of channel } & & Transaction tendency \\
\hline & & \multirow[t]{3}{*}{ Cooperative intention } & Transaction urgency \\
\hline & & & Brand building intention \\
\hline & & & Inventory capacity \\
\hline & & \multirow[t]{3}{*}{ Operation capacity } & Logistics management capacity \\
\hline & & & Impact resistance of channel \\
\hline & \multirow{6}{*}{ Expansibility of channel } & & Market coverage \\
\hline & & \multirow[t]{2}{*}{ Competitive capacity } & Brand communication capacity \\
\hline & & & Credit and social approval degree \\
\hline & & \multirow{3}{*}{$\begin{array}{c}\text { Sustainable } \\
\text { development } \\
\text { capacity }\end{array}$} & E-commerce capacity \\
\hline & & & Management innovation capacity \\
\hline & & & Training system perfect degree \\
\hline
\end{tabular}

the same pattern, and different brands share the same channel. Brand out caused by channel extrusion is the biggest channel crisis faced by painting material enterprises. Therefore, evaluation on cooperative intention of the channel is very important during channel selection, especially evaluation on whether channel partners are willing to help painting material enterprises build and transfer more brand information to consumers by utilizing their terminal resources. Secondly, in order to stably realize transition and circulation, channels require a certain operation capacity. Thereby, this paper evaluates the stability of channel from cooperative intention and operation capacity of the channel. The specific indexes of cooperative intention include transaction tendency, transaction urgency and brand building intention; the specific indexes of operation capacity cover inventory capacity, logistics management capacity and impact resistance of channel.

3) Evaluation on expansibility of channel. Most enterprises consider that "channel is the king" or "victory can be gained via brand", but they have ignored the relation between channel and brand. A competitive channel should be consistent with channel positioning and brand positioning, and able to become a platform of building brand. On the other hand, channel is not changeless and channel development must adapt to environmental changes. Especially after modern channels (such as e-commerce) get involved, traditional channels are faced with huge competition pressure. Therefore, only through continuous learning and improvement, can competitive advantages of the channel be maintained in long-term development. Thereby, this paper evaluates the expansibility of channel from competitive capacity and sustainable development capacity of the channel. The evaluation indexes of competitive capacity include market coverage, brand communication capacity, and credit and social approval degree; the evaluation indexes of sustainable development capacity cover e-commerce capacity, management innovation capacity and training system perfect degree.

\section{Channel Selection Evaluation Model of Painting Material Industry}

There are at least three key points when constructing a channel selection evaluation model via analytic hierarchy process. Firstly, the channel selection evaluation model should be determined. Secondly, various index weights must be determined by directing at different influence factors. Thirdly, how to apply the research results of channel selection evaluation model to practical management decision-making of enterprises should be determined. 


\subsection{Model Building for Channel Selection via Analytic Hierarchy Process}

According to the channel selection evaluation index system of painting material industry established above, the evaluation model is constructed through analytic hierarchy process, as shown in Figure 1. In order to make the calculation convenient, this paper does not bring factors of sub-goal layer in the index system into the evaluation model during model building. The model is directly simplified into three layers, goal layer (A), Criterion layer (B) and index layer (C).

\subsection{Design of Various Index Weights}

In this paper, weights of various factors are determined by adopting paired comparison method. Firstly, paired comparison is conducted for each factor successively, so as to judge the relative importance of two factors. Then weights of various factors are gained via specification column average method, and consistency check is carried out. If the check is passed, it means that the weight, i.e. feature vector is effective.

1) Establishment of two-two comparison matrix. In order to determine weights of various factors, the relative importance scale during two-two comparison of factors should be decided, as shown in Table 2.

By combining with relevant materials and literatures as well as channel characteristics of painting material industry, two-two comparison is conducted for factors at criterion layer including distribution efficiency, transaction cost, cooperative intention, operation capacity, competitive capacity and sustainable development capacity. The judgment matrix is obtained via expert scoring, as shown in Table 3.

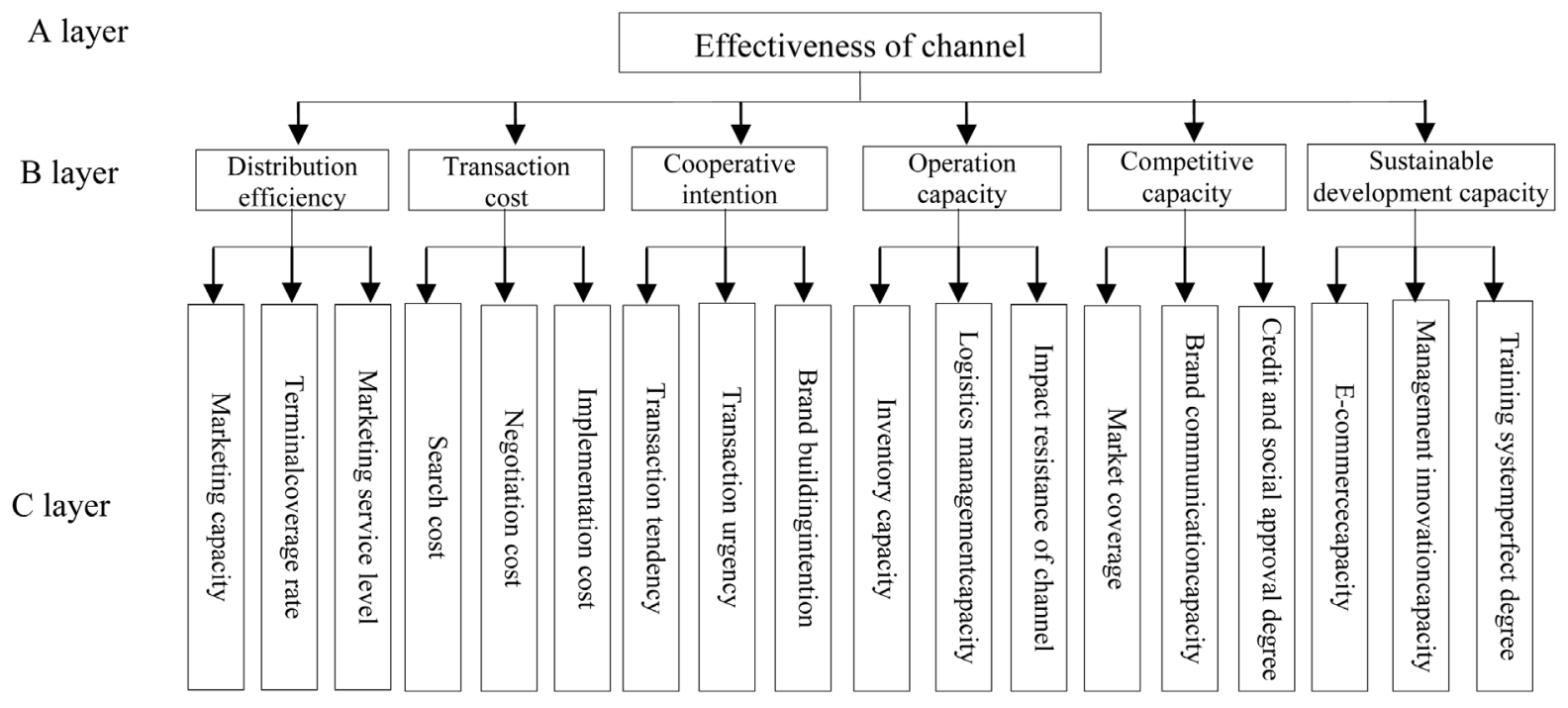

Figure 1. Channel selection model of painting material industry via analytic hierarchy process.

Table 2. Scale of relative importance.

\begin{tabular}{|c|c|}
\hline Scale & Implication \\
\hline 1 & The two elements are equally important during comparison \\
\hline 3 & The former element is slightly more important than the latter element during comparison \\
\hline 5 & The former element is obviously more important than the latter element during comparison \\
\hline 7 & The former element is strongly more important than the latter element during comparison \\
\hline 9 & The former element is extremely more important than the latter element during comparison \\
\hline $2,4,6,8$ & Intermediate value of the above adjacent judgments \\
\hline Reciprocal & $\begin{array}{l}\text { If the importance ratio between element } i \text { and element } j \text { is } a_{i j} \text {, } \\
\text { then the importance ratio between element } j \text { and element } i \text { is } \mathrm{a}_{j i}=1 / \mathrm{a}_{i j}\end{array}$ \\
\hline
\end{tabular}


Table 3. Judgment matrix of factors at criterion layer.

\begin{tabular}{ccccccc}
\hline Factors & $\begin{array}{c}\text { Distribution } \\
\text { efficiency }\end{array}$ & $\begin{array}{c}\text { Transaction } \\
\text { cost }\end{array}$ & $\begin{array}{c}\text { Cooperative } \\
\text { intention }\end{array}$ & $\begin{array}{c}\text { Operation } \\
\text { capacity }\end{array}$ & $\begin{array}{c}\text { Competitive } \\
\text { capacity }\end{array}$ & $\begin{array}{c}\text { Sustainable } \\
\text { development capacity }\end{array}$ \\
\hline Distribution efficiency & 0.3743 & 0.4629 & 0.2647 & 0.3352 & 0.4213 & 0.4211 \\
Transaction cost & 0.0579 & 0.0712 & 0.0882 & 0.0652 & 0.0351 & 0.0702 \\
Cooperative intention & 0.0842 & 0.0534 & 0.0588 & 0.0596 & 0.0321 & 0.0702 \\
Operation capacity & 0.2807 & 0.2493 & 0.2353 & 0.2235 & 0.1805 & 0.2105 \\
Competitive capacity & 0.1092 & 0.0208 & 0.2353 & 0.1676 & 0.1204 & 0.1228 \\
$\begin{array}{c}\text { Sustainable } \\
\text { development capacity }\end{array}$ & 0.0936 & 0.1424 & 0.1176 & 0.1490 & 0.2106 & 0.1053
\end{tabular}

2) Weights of various factors. In this paper, weights of various factors are gained via specification column average method. Firstly, summation is conducted for each column and each numerical value in the column is divided by the sum value. The quotients form a standard two-two comparison matrix. Finally, the average values in each line of standard two-two comparison matrix are calculated, and these average values are weights of various factors [8]. Table 4 shows the calculation results.

3) Consistency check. Generally speaking, the consistency ratio $C R$ is used to judge whether the matrix has satisfying consistency, $C R$ is defined as

$$
\begin{gathered}
C R=C I / R I \\
C I=\left(\lambda_{\max }-n\right) /(n-1)
\end{gathered}
$$

$\lambda_{\max }$ is the maximum eigenvalue of judgment matrix; $R I$ is the average random consistency index value of judgment matrix. After calculation, $C R=0.0543<0.1$. Therefore, judgment matrix of this weight investigation has good consistency and the weight value can be used.

\subsection{Evaluation on Effectiveness of Channel Selection}

Assignment is conducted for the 18 factors at index layer via five-level Likert scale. The factor score at criterion layer is calculated as

$$
B_{i}=\frac{\sum_{j=1}^{n_{i}} C_{i j}}{n_{i}}
$$

where $B_{i}$ means factor $i$ at criterion layer, $C_{i j}$ represents index $j$ under $B_{i}$, and $n_{i}$ signifies number of factors at index layer under $B_{i}$ at criterion layer.

According to the factor score at criterion layer and various factor weights, the score at goal layer $A$ is calculated as

$$
A=\sum_{i=1}^{6} W_{i} B_{i}
$$

where $W_{i}$ is the weight of factor $i$ at criterion layer $B_{i}$. According to the effectiveness score of different channels, advantages and disadvantages of the channels can be evaluated, which will help enterprises choose the optimal channel.

\subsection{Application of the Model}

In this paper, application of the model is verified by taking a painting material enterprise of local brand in Shenzhen as an example. This company plans to establish new channels in South China and now there are three feasible schemes. Firstly, it is self-built channel (D1) including retail channels like professional stationery stores and chain supermarkets. Secondly, it comes to online channel (D2) including professional websites such as Amazon, JD. COM and dangdang.com. Thirdly, it is offline wholesale and agent channel (D3). 
According to the practical situations of the three channels, expert group is invited to grade and assign the 18 factors at index layer as per five-level Likert scale. Table 5 shows the specific scores.

After calculation, the contribution of channel D1 to B1 at C layer is

$$
(3.9434+3.8736+4.1245) / 3=3.9805
$$

Similarly, the contributions of D1 to B2, B3, B4, B5 and B6 are 3.6400, 3.8648, 3.6396, 3.6898 and 3.5927 respectively, and the contribution of channel D1 to $A$ is

$$
\begin{aligned}
A= & 3.9805 * 0.3799+3.6400 * 0.0646+3.8648 * 0.0597+3.6396 * 0.2300 \\
& +3.6898 * 0.1293+3.5927 * 0.1364=3.7823
\end{aligned}
$$

Besides, the contributions of D2 and D3 to $A$ are calculated and the results are 3.7744 and 3.5881. Therefore, the priority order of the three channels is D1, D2 and D3.

Table 4. Determination for factor wrights via paired comparison method.

\begin{tabular}{|c|c|c|c|}
\hline Channel & D1 & D2 & D3 \\
\hline C1 & 3.9434 & 3.8538 & 4.1115 \\
\hline C2 & 3.8736 & 3.985 & 3.3568 \\
\hline C3 & 4.1245 & 3.7892 & 3.5323 \\
\hline C4 & 3.7213 & 3.7019 & 3.8034 \\
\hline C5 & 3.5628 & 3.6529 & 3.8472 \\
\hline C6 & 3.6358 & 3.8063 & 3.7356 \\
\hline C7 & 3.8736 & 3.8623 & 3.6754 \\
\hline C8 & 3.7358 & 3.3207 & 3.8649 \\
\hline C9 & 3.9849 & 3.2875 & 3.0824 \\
\hline C10 & 3.6849 & 3.7843 & 3.6793 \\
\hline C11 & 3.6113 & 3.6829 & 3.7282 \\
\hline C12 & 3.6226 & 3.7722 & 3.3419 \\
\hline C13 & 3.4491 & 3.783 & 3.5465 \\
\hline C14 & 3.7377 & 3.6172 & 3.4291 \\
\hline C15 & 3.8826 & 3.902 & 3.5829 \\
\hline C16 & 3.5836 & 3.8823 & 3.4718 \\
\hline C17 & 3.8736 & 3.8538 & 4.1115 \\
\hline C18 & 4.1245 & 3.985 & 3.3568 \\
\hline
\end{tabular}

\begin{tabular}{cc}
\hline Factors & Distribution efficiency \\
\hline Distribution efficiency & 0.3799 \\
Transaction cost & 0.0646 \\
Cooperative intention & 0.0597 \\
Operation capacity & 0.2300 \\
Competitive capacity & 0.1293 \\
Sustainable development capacity & 0.1364 \\
\hline
\end{tabular}

Table 5. Factor scores at index layer of three channels. 


\section{Conclusion}

By directing at the severe brand overlapping phenomenon of painting material industry and channel characteristics of furious competition for terminal resources, it is quite necessary for painting material enterprises to consider brand building when selecting new channels. The evaluation model of channel selection in painting material industry is established via analytic hierarchy process, and comprehensive evaluation is conducted for distribution efficiency, transaction cost, cooperative intention, operation capacity, competitive capacity and sustainable development capacity of channels. It will help enterprises choose a channel that can provide a basic platform for brand development and that can support and cooperate with brand communication and improvement. Therefore, painting material enterprises are able to obtain differentiated competitive advantages.

\section{References}

[1] Tian, G.P. and Liu, B. (2009) Matching Relation between Brand Building and Channel Building-Exploration on the Development Road of “China •Alcoholic Store”. Modern Economics, 2, 62-63.

[2] Louis, W. and Stern, A. (2001) Marketing Channels. 5th Edition, Tsinghua University Press, Beijing.

[3] Li, J.J. (2010) Study on Performance Evaluation of Enterprise Marketing Channels. M.B.A. Thesis, Xidian University, Xi'an.

[4] Han, L.J. and Fan, G.Y. (2006) Construction of Marketing Channel Evaluation Index System. Entrepreneurial Studies, 6, 20-21.

[5] Wang, Y.J. (2007) Study on Marketing Channel Performance Evaluation Index System of C Enterprise. M.B.A. Thesis, Nanjing University of Science and Technology, Nanjing.

[6] Ye, N. (2013) Selection Evaluation Model Building and Demonstration of Channel Partners. Statistics and Decision, 16, 36-38.

[7] Zhao, X.F. (2008) Marketing Channel Competitiveness Evaluation Model and Empirical Research. Marketing Research, 1, 30-35.

[8] Deng, X., Li, J.M. and Zeng, H.J. (2012) Research on Computation Methods of AHP Wight Vector and Its Applications. Mathematics in Practice and Theory, 7, 93-100. 